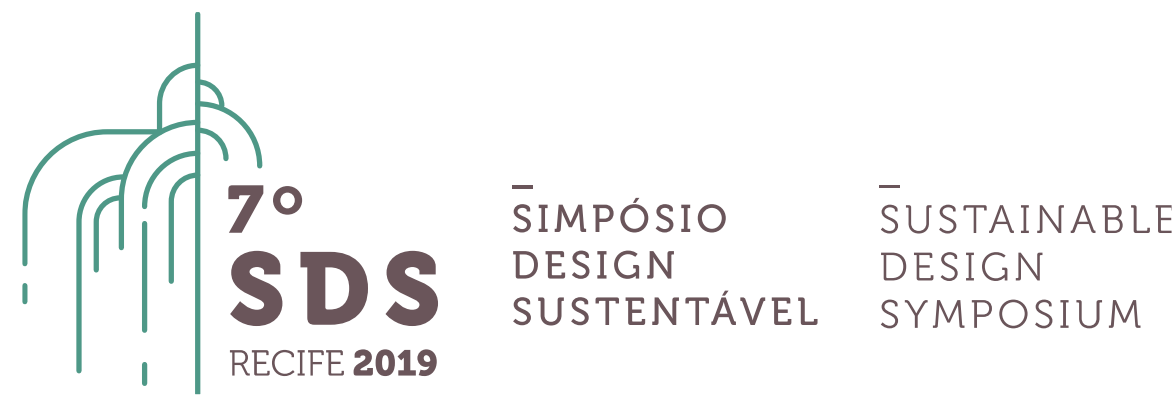

\title{
Design de um Catamarã de Transporte Urbano para o Rio Capibaribe
}

\author{
Ênio Lustosa Roriz ${ }^{1}$, Cesar Augusto Salhua Moreno² \\ ${ }^{1}$ Universidade Federal de Pernambuco, Departamento de Engenharia Mecânica (DEMEC), Curso de \\ Engenharia Naval, eniorlustosa@hotmail.com \\ ${ }^{2}$ Universidade Federal de Pernambuco, Departamento de Engenharia Mecânica (DEMEC), Curso de \\ Engenharia Naval, cesar.salhua@ufpe.br
}

Resumo. $O$ presente trabalho apresenta o desenvolvimento do projeto conceitual de uma embarcação de transporte de passageiros para à navegação no Rio Capibaribe. Para ser utilizada como alternativa de meio de transporte público, visto que Recife é uma cidade com grandes congestionamentos. Porém, é uma cidade agraciada com diversos recursos naturais, por exemplo ser cortada por rios, sendo assim, alguns autores denominam a cidade de "Veneza Brasileira". O principal Rio é o Capibaribe, que percorre aproximadamente $14 \mathrm{~km}$ dentro do Recife. Este trabalho utiliza como base o Projeto Navega Recife, desenvolvido pela Secretaria das Cidades do Estado de Pernambuco, para o qual estava previsto a construção de 13 embarcações com capacidade de 86 passageiros. Este projeto tem como objetivo a locomoção de passageiros que poderiam ser transportados na rota compreendida entre o shopping Tacaruna à BR 101, nas mediações da Avenida Caxangá. Esta rota é dividida em dois corredores: norte e oeste. As etapas de desenvolvimento do projeto são estruturadas mediante um fluxograma, elaborado para atender aos requisitos exigidos pelo projeto Navega Recife. O início das etapas do projeto se deu com a determinação das dimensões da embarcação, em seguida a forma, arranjo geral, topologia estrutural, estabilidade, sistema propulsivo, finalizando com a avaliação econômica. Como resultado, é desenvolvido o projeto de uma embarcação de fibra de vidro, com 14 metros de comprimento e com capacidade para 86 pessoas, onde deve levar em média 36 minutos para percorrer os $11 \mathrm{~km}$ de percurso do corredor oeste.

Palavras-chave. Projeto Conceitual; Catamarã; Rio Capibaribe; Uso adequado das águas; Metodologias de projeto; Mobilidade. 
Abstract. The present work presents the development of the project of a passenger boat for Capibaribe river navigation as a public transportation alternative. Due to Recife is a city with great congestion, however, it has several natural resources, for example to be cut by rivers, so some authors call the city as "Brazilian Venice". The main river is Capibaribe, which runs approximately $14 \mathrm{~km}$ inside Recife. This work is based on the Navega Recife Project, developed by the Cities Department of Pernambuco State. This project consists in the construction of 13 inland vessels with a capacity of 86 passengers. This project aims to transport passengers from the Tacaruna mall to $B R 101$, in the mediations of Caxangá Avenue. The development of this project follows the steps organized through a flow chart. These was elaborated based on the steps of the project to fit the requirements demanded by the Navega Recife project. The beginning of the project is based on the dimensions of the vessel, then forming, general arrangement, structural topology, stability, propulsive system, ending with an economic evaluation. As a result, the project of a 14-meter long boat with a capacity for 86 people is expected to take an average of 36 minutes to cover the $11 \mathrm{~km}$ of the course.

Key words. Conceptual Design; Catamaran; Rio Capibaribe; Proper use of water; Project methodologies; Mobility.

\section{Sustentabilidade da Navegação no Rio Capibaribe}

O Rio Capibaribe nasce na serra de Jacarará, município de Poção e deságua no Oceano Atlântico, tem $270 \mathrm{~km}$ de extensão total. Seu estuário atravessa a Região Metropolitana do Recife (RMR), percorre cerca de 17 bairros e tem uma extensão dentro da cidade de $14 \mathrm{~km}$. Seu nome vem da língua tupi Caapiuar-y-be ou Capibara-ybe que significa "rio das capivaras" ou "rio dos porcos selvagens" (HOLANDA, 2012), em virtude a abundante fauna que existia nas suas margens. Foi na sua várzea que os primeiros engenhos de açúcar apareceram, nas suas águas eram transportados os produtos produzidos até o porto de Recife e era trazida água potável do Riacho da Prata. Foi fundamental para o desenvolvimento econômico dessa época, com o fim dos engenhos e a modernização da cidade, a utilização do Rio Capibaribe como hidrovia de transporte de carga foi desaparecendo. Esta situação empiorou com a desativação do porto de Recife para transporte de cargas, devido a criação do porto de Suape. A explosão populacional e expansão urbana sem planejamento contaminou o rio, com esgoto e lixo despejado diretamente, de tal forma que nem podia ser utilizado para atividades de recreio e lazer. Desta forma, o rio Capibaribe passou a não ser parte importante da economia da região e encontra-se aparentemente abandonado.

Como toda grande cidade, Recife sofre com engarrafamentos veiculares intensos (SANTOS; FERRINHO; ROMÃO, 2011). Estes produzem consequências na população como desconforto, poluição ambiental, ruído excessivo, problemas de saúde e emperramento do crescimento econômico. (DE ARAUJO et al., 2015).

A navegação no Rio Capibaribe seria uma alternativa que ajudaria aliviar grande parte do problema de transporte urbano da cidade, porque ofereceria uma rota sem congestionamentos entre o Shopping Tacaruna (Olinda) e á BR 101, nas mediações da Avenida Caxangá (RMR). Porém, o curso do rio deve ser acondicionado para se converter numa hidrovia segura. Estes trabalhos de 
acondicionamento não se concentram somente na dragagem do rio, para o incremento de calado, e construção de estações. O foco principal se concentra em resolver os problemas de contaminação ambiental, produzidos pelo esgoto doméstico não tratado e produtos químicos despejados diretamente no Capibaribe, principalmente na região metropolitana de Recife. Para o qual é necessário que a COMPESA incremente o tratamento de esgoto, que na atualidade chega a somente $25 \%$ (NASCIMENTO, 2017). Soma-se a este cenário o lixo descartado diretamente no rio pelas populações ribeirinhas, para isto ser evitado seria necessária uma maior conscientização da população.

O desenvolvimento de um projeto de navegação do Rio Capibaribe é uma oportunidade de resgate e revitalização deste, porque promoveria sua despoluição para garantir a segurança da navegação. No presente trabalho descreve-se unicamente o projeto de uma embarcação do tipo catamarã que atenderá os requerimentos técnicos do Projeto Navega Recife, descrito a seguir.

\subsection{Navegação no Rio Capibaribe: Projeto Navega Recife}

O projeto Navega Recife original, tem como objetivo a implementação de dois corredores fluviais, o corredor norte, com $2,9 \mathrm{~km}$ de extensão e o corredor oeste, com $11 \mathrm{~km}$ de extensão (CAMARA et al., 2014). A separação entre os corredores é devido a duas pontes: Ponte Duarte Coelho e Ponte Boa vista. Pois estas pontes têm altura de 1,29 metros e 1,05 metros, respectivamente, tornando impossível a passagem de uma embarcação. Este projeto visa a construção de 5 estações (Metrô/Recife, Derby, Torre, Santana, Apipucos), 13 embarcações e 156 viagens por dia, cada embarcação deve fazer 12 viagens, onde as embarcações devem ter capacidade para o transporte de 86 passageiros sentados e velocidade média de 9,7 nós (CAMARA et al., 2014). A profundidade máxima do percurso é de 2,50 metros (GOVERNO DO ESTADO DE PERNAMBUCO, 2016).

Esta velocidade média utilizada leva em consideração o tempo parado nas estações. Para fazer o dimensionamento da velocidade de navegação real da embarcação, retira-se o tempo que a embarcação deve passar parada em cada estação considerando que cada embarcação deve fazer 12 viagens por dia. São 5 estações, sendo que nas estações extremas, a embarcação passa mais tempo parada do que nas estações intermediárias, então foi considerado que a embarcação passará 6 minutos em cada estação extrema e 3 minutos em cada estação intermediária, com essas considerações a embarcação precisaria ter uma velocidade de navegação de 23 nós para poder percorrer todo o corredor em 36minutos.

Figura 1

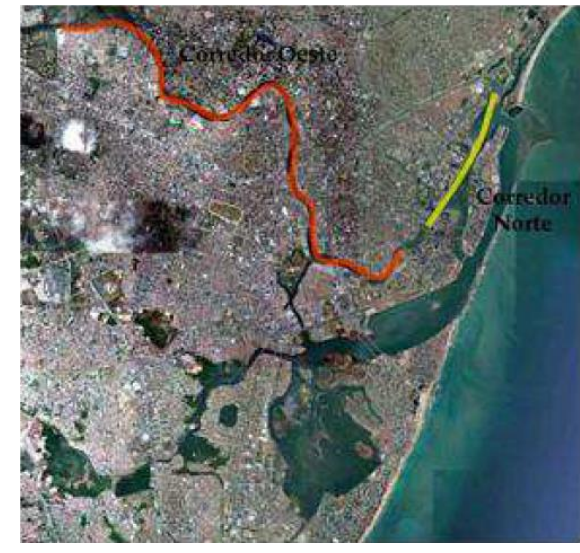

Rotas do Rio Capibaribe.

Fonte: CAMARA et al., 2014 


\subsection{Pontes do Recife}

As pontes são os principais fatores limitantes das dimensões da embarcação. Por ser uma cidade cortada por rios, sendo eles, os Rios Capibaribe e Beberibe, o Recife possui diversas pontes para fazer a ligação entre as regiões. Algumas das pontes foram construídas no século XVII, época em que Recife foi escolhida para ser sede da administração flamenga, colônia holandesa (ANGÉLICA, 2011). As pontes que estão no trajeto da embarcação são: Ponte Joaquim Cardoso, Ponte José de Barros Lima (Capitão Temudo), Ponte Professor Lima de Castro, Ponte Estácio Coimbra, Ponte Professor Moraes Rego, Ponte Engenheiro Cândido Pinto de Melo, Ponte do Vitem, Passarela Santana/Zumbi.

Todas as dimensões das pontes apresentadas neste trabalho foram obtidas através do governo do estado, pela secretaria das Cidades. As pontes que influenciam no corredor oeste estão apresentadas na Tabela 1.

Tabela 1

\begin{tabular}{|l|l|l|}
\hline & \multicolumn{2}{|l|}{ Dimensões } \\
\hline Pontes & $\begin{array}{l}\text { Boca } \\
(\mathrm{m})\end{array}$ & Altura livre $(\mathrm{m})$ \\
\hline Ponte Joaquim Cardoso & 37 & 5,56 \\
\hline Ponte José de Barros Lima (Capitão Temudo) & 37 & 4,35 \\
\hline Ponte Professor Lima de Castro & 37 & 4 \\
\hline Ponte Estácio Coimbra & 37 & 3,54 \\
\hline Ponte Professor Moraes Rego & 37 & 3,83 \\
\hline Ponte Engenheiro Cândido Pinto de Melo & 37 & 3,89 \\
\hline Ponte do Vintem & 37 & 5,95 \\
\hline Passarela Santana/Zumbí & 37 & 2,61 \\
\hline \multicolumn{1}{|c|}{ Tabela com as dimensões das pontes. } \\
\hline
\end{tabular}

Levando em consideração que a Passarela Santana/Zumbí é a de menor altura, esta foi a ponte que limitou a altura da superestrutura (teto da embarcação).

\section{Design Do Catamarã}

Um fluxograma de projeto foi elaborado para organizar as etapas de desenvolvimento da embarcação. Utilizam-se os requerimentos do projeto Navega Recife como fatores de projeto a serem atendidos, a ordem das etapas é seguinte: dimensões principais, forma do casco, arranjo geral, topologia estrutural, estabilidade, sistema propulsivo e viabilidade econômica.

\subsection{Dimensões principais}

Um levantamento do comprimento (L), boca (B), pontal (D) e deslocamento (peso) de embarcações semelhantes é realizado. Porém, muitas dessas informações são bastante restritas, fazendo com que o projetista se veja obrigado a trabalhar com poucas informações no início do projeto. Todas as informações encontradas são colocadas em gráficos em função do número de passageiros, onde é realizada uma regressão polinomial para obter formulações que permitam obter as dimensões principais, por exemplo veja-se as seguintes figuras: 
Figura 2

$\mathrm{n}^{\circ}$ de passageiros VS L

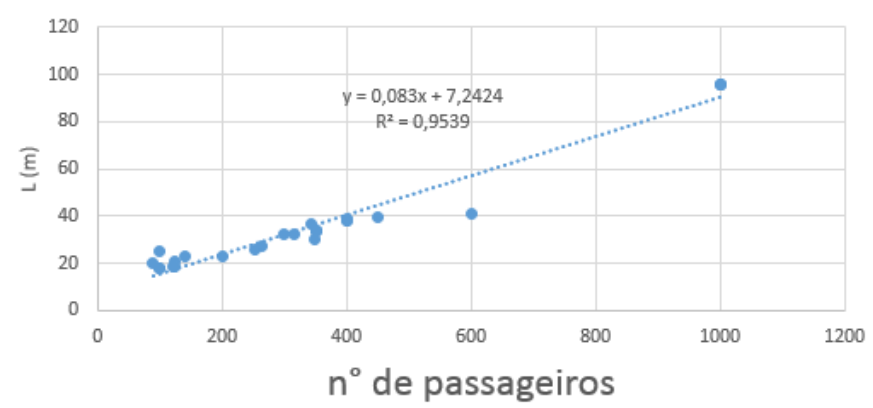

$\mathrm{n}^{\circ}$ de passageiros VS B

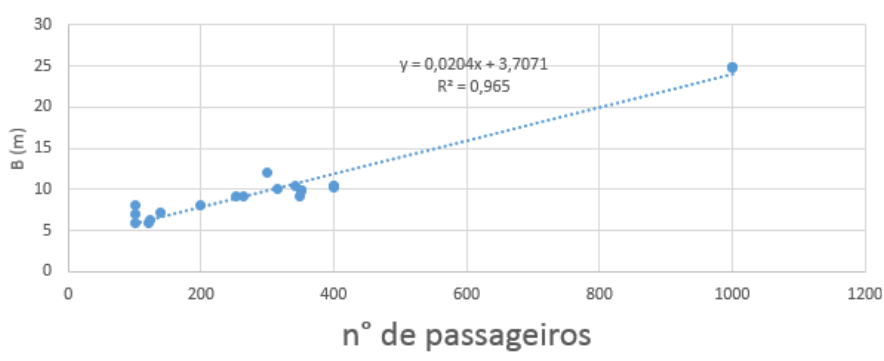

$\mathrm{n}^{\circ}$ de passageiros VS Deslocamento

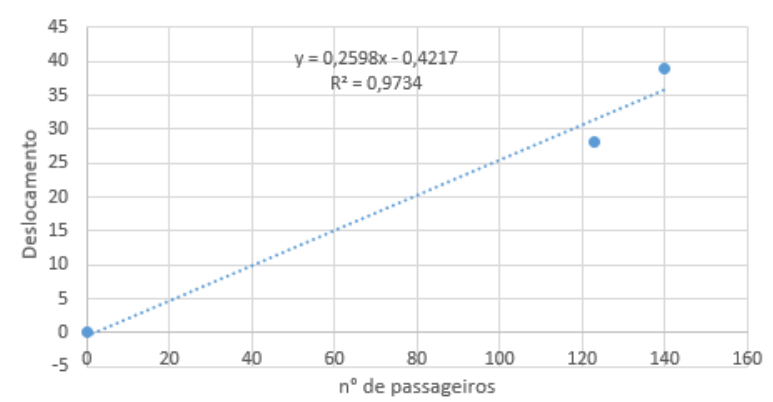

$\mathrm{n}^{\circ}$ de passageiros VS D

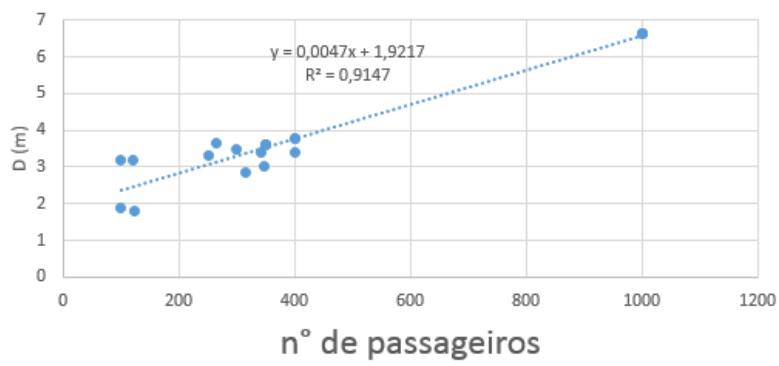

Gráficos do Comprimento, Deslocamento, Boca e Pontal em função do $\mathrm{n}^{\circ}$ de passageiros Fonte: autor

\subsection{Forma}

A forma dos cascos foi desenvolvida a partir de um catamarã base fornecido pelo software de Engenharia Naval MAXSURF, onde foram modificados alguns parâmetros com o objetivo de diminuir a resistência ao avanço e a sua complexidade de construção, assim obter um casco mais eficiente. Com isso, obteve-se o casco mostrado nos planos de linhas nas seguintes figuras:

Figura 3
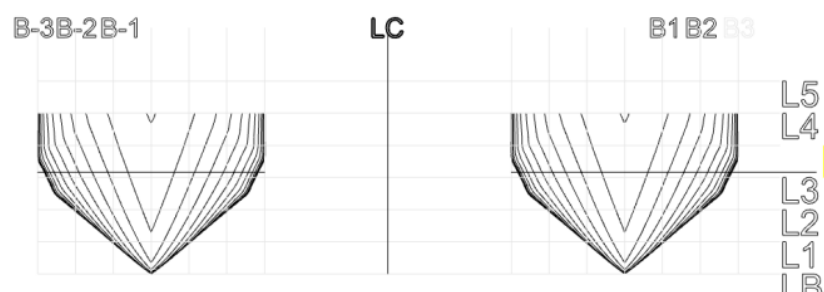

Vista transversal do catamarã.

Fonte: Autor

Figura 4

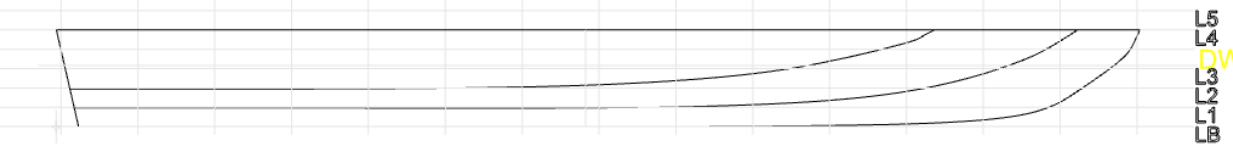

Zero pt.

Vista longitudinal do catamarã.

Fonte: Autor 
Figura 5

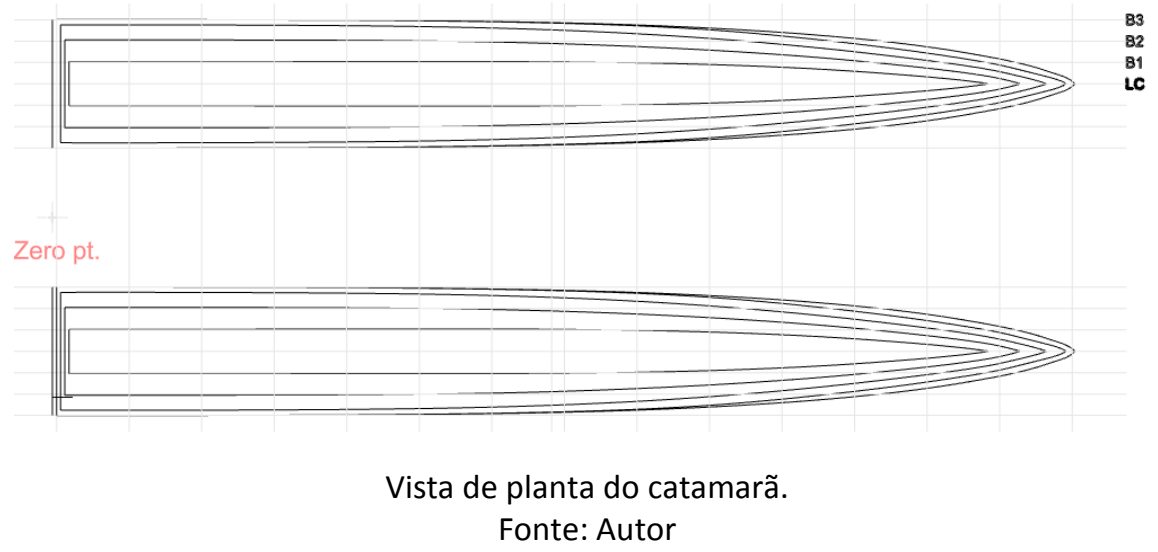

Considerando 86 passageiros, especificação do projeto Navega Recife, é necessário um catamarã com as dimensões mostradas na Tabela 2. 0 pontal foi adaptado para 1,25 metros, com isso facilitando na dimensão da altura da superestrutura devido à altura das pontes.

Tabela 2

\begin{tabular}{|l|l|l|}
\hline L & 14,01 & $\mathrm{~m}$ \\
\hline B & 5,46 & $\mathrm{~m}$ \\
\hline D & 1,25 & $\mathrm{~m}$ \\
\hline B do casco & 1,77 & $\mathrm{~m}$ \\
\hline T & 0,79 & $\mathrm{~m}$ \\
\hline
\end{tabular}

Dimensões principais determinadas por navios semelhantes.

Fonte: Autor

\subsection{Arranjo geral}

A superestrutura de uma embarcação é a região onde os passageiros e tripulação são alocados durante a viagem. Esta foi projetada considerando a acessibilidade de pessoas em cadeira de rodas e conforto durante a viagem, por esse motivo está é fechada e refrigerada por um sistema de ar condicionado. De início foram feitas várias tentativas para acomodar os 86 passageiros (dois lugares para cadeiras de rodas), espaço para o banheiro e cabine do comandante e por fim obteve-se a última versão que está representada nas Figuras 5, 6 e 7.

As dimensões do pé direito, do corredor, das cadeiras e o campo de visão do piloto foram definidas através da Norma de Autoridade Marítima para navegação interior, NORMAM-02, as dimensões do banheiro e do espaço da cadeira de rodas foram definidas pela ABNT NBR 9050, com estas definições, foi possível definir o arranjo geral. 


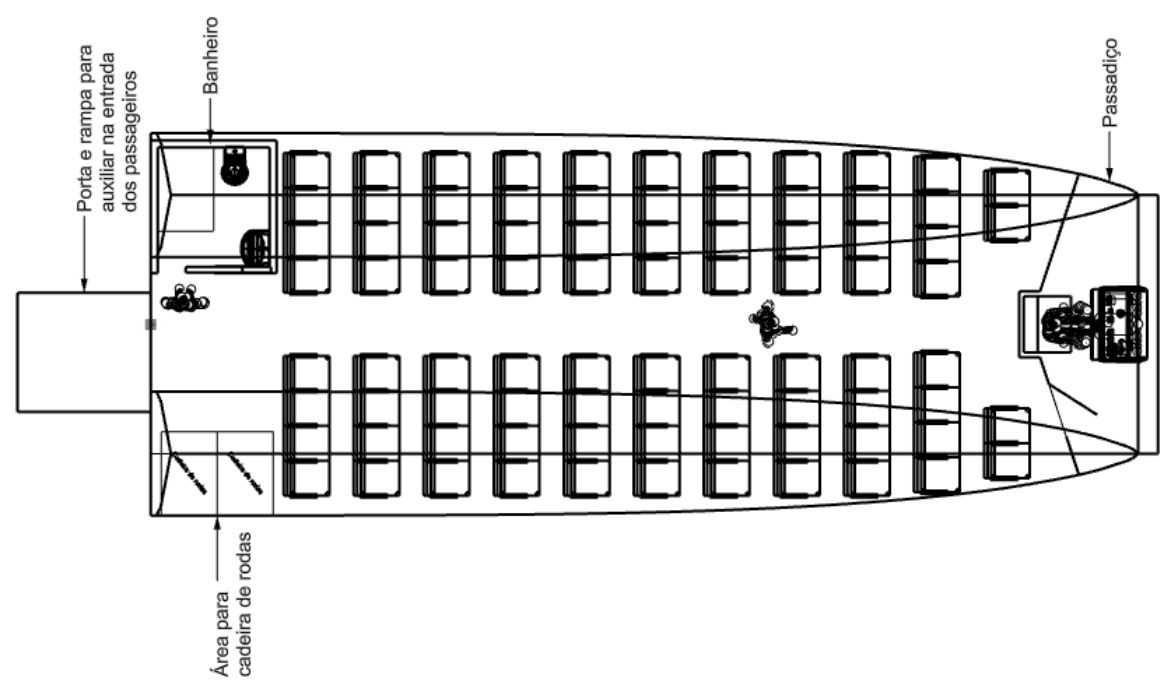

Vista de planta do arranjo geral.

Fonte: Autor

Figura 7

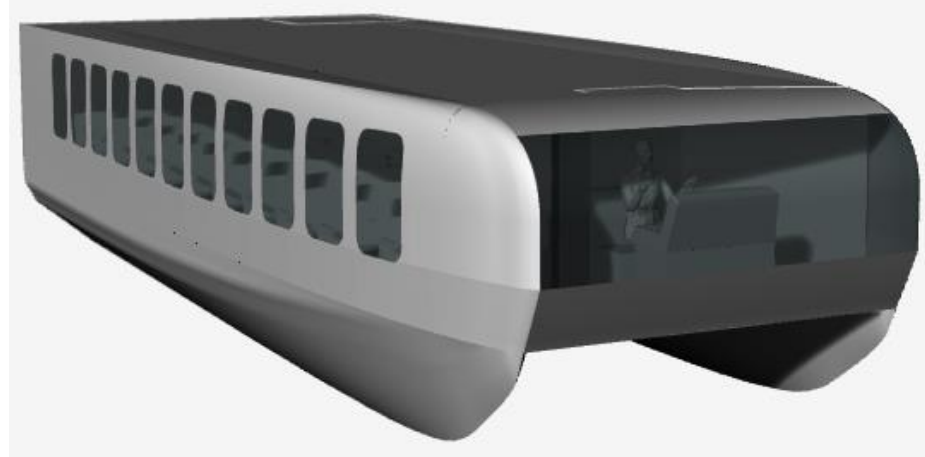

Ilustração da embarcação.

Fonte: Autor

Figura 8

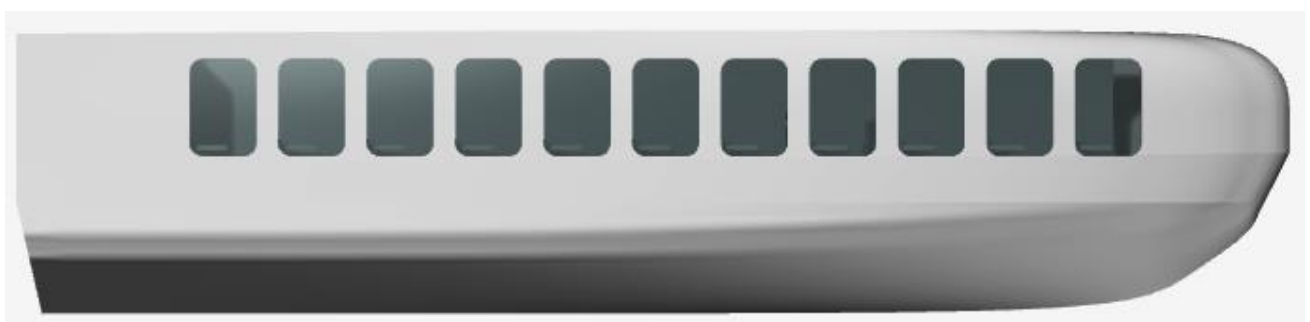

Vista longitudinal da embarcação.

Fonte: Autor

\subsection{Topologia estrutural}

O material de construção da embarcação precisa cumprir com uma série de requerimentos técnicos de resistência e durabilidade. A pesar do impacto ambiental que a utilização da fibra de vidro com resina poliéster representam, este material será utilizado. Porque oferece segurança para a vida dos passageiros durante a navegação e no Recife existem vários estaleiros que trabalham com fibra de vidro, e onde a construção da embarcação poderia ser realizada. 
Infelizmente a utilização de fibras orgânicas ainda está em estágio de desenvolvimento. O dimensionamento da topologia estrutural da embarcação foi desenvolvido com base nas regras para construção de embarcações de fibra de vidro da sociedade classificadora American Bureau of Shipping (ABS), esta fornece diversas formulações para cada item a ser dimensionado.

Desta forma, a espessura do laminado e das anteparas são de $9 \mathrm{~mm}$ e 1,6 mm, respectivamente. $O$ módulo de seção dos reforços longitudinais do convés, do costado, do fundo e da superestrutura são $38,8 \mathrm{~cm}^{3}, 14 \mathrm{~cm}^{3}, 27 \mathrm{~cm}^{3}$ e $13 \mathrm{~cm}^{3}$, respectivamente. $O$ dimensionamento das vigas transversais do convés, que são as vigas que fazem a ligação entre os dois cascos, resultou $238 \mathrm{~cm}^{3}$, onde foi dimensionado 5 vigas com módulo de seção de $286 \mathrm{~cm}^{3}$ para atender aos requisitos das normas.

Com os módulos de seção mínimos exigido pela classificadora dimensionados, foi possível padronizar a dimensão do reforço a ser utilizado na embarcação, sendo este reforço apresentado na Figura 8, com módulo de seção de $49,4 \mathrm{~cm}^{3}$, atendendo a todos os reforços exigidos.

Figura 9
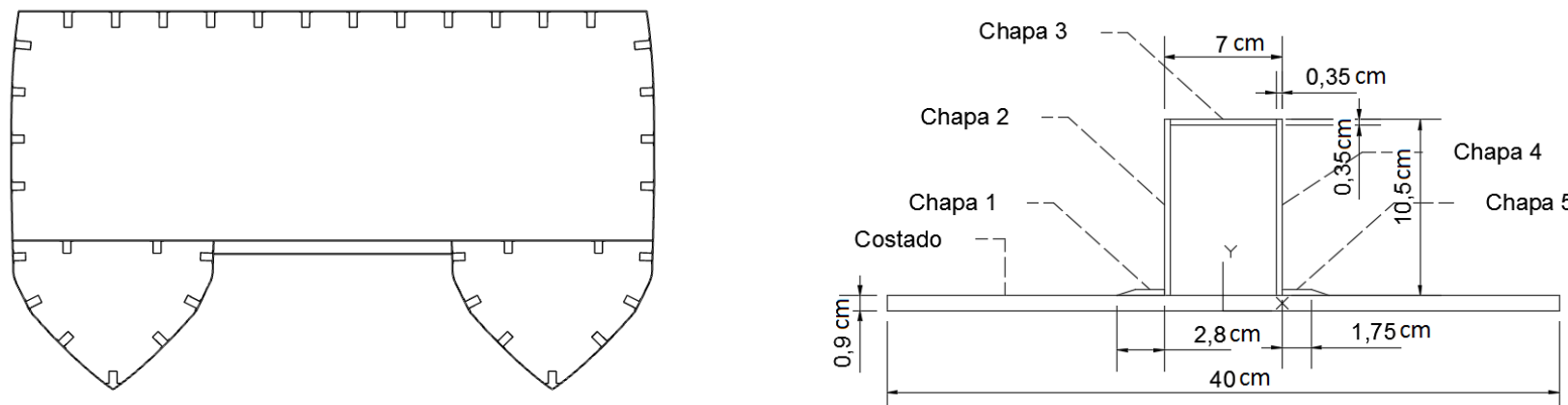

Seção transversal da topologia estrutural do catamarã / Dimensões e representação do reforço padronizado Fonte: Autor

\subsection{Estabilidade da embarcação}

A estabilidade transversal de uma embarcação consiste na capacidade de continuar flutuando (com e sem avarias) mesmo quando esta seja afetada por vento, ondas, correntezas ou outras embarcações. A estabilidade é avaliada mediante o valor do braço de restauração GZ para cada ângulo de inclinação transversal da embarcação. Os valores são obtidos com o auxílio do software Maxsurf Stability. Nesta curva analisa-se à área compreendida pela curva GZ, o braço máximo e o ângulo correspondente, entre outras variáveis. A verificação destas variáveis para definir se a embarcação possui estabilidade ou não é feita comparando com valores mínimos obtidos na NORMAM-02. A seguir apresentam-se duas curvas GZ do catamarã sem e com avarias no casco:

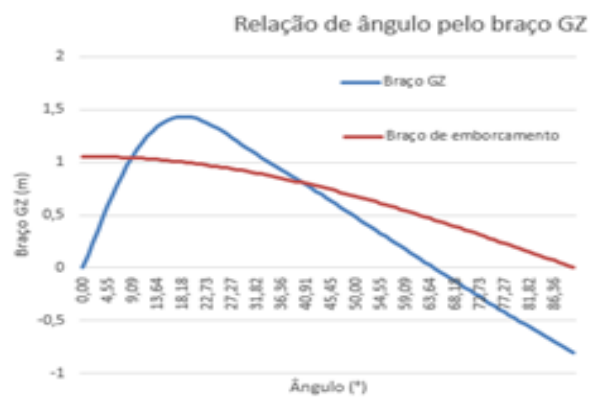

Sem avarias no casco
Figura 10

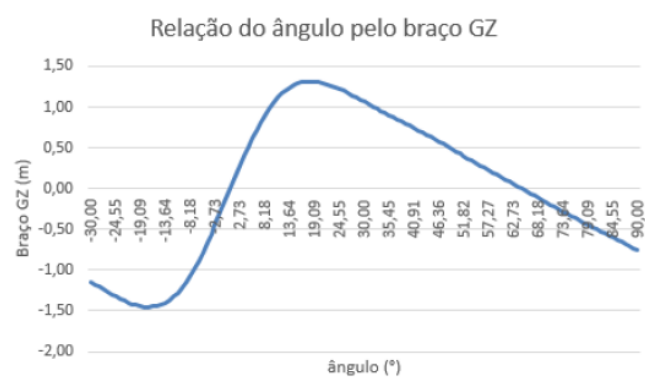

Com avarias no casco

Braço de restauração GZ em função do ângulo de inclinação transversal Fonte: Autor 
Para a análise da estabilidade através da NORMAM-02 a embarcação precisa atender a 6 condições de carregamento e cada condição precisa atender a 5 critérios de estabilidade, no presente caso, a embarcação atendeu todos os critérios.

\subsection{Sistema propulsivo da embarcação}

Para garantir a velocidade de operação do catamarã (23nós) precisou-se utilizar motores diesel marinhos, que atendam os requerimentos de emissão de poluentes da Organização Marítima Internacional (IMO), Comunidade Europeia (EU) e da Agência de Proteção ao Meio Ambiente dos Estados Unidos (EPA): IMO NOx, EU RCD Stage II e USA EPA tier3, respectivamente.

O dimensionamento do sistema propulsivo da embarcação se inicia com a análise da resistência ao avanço e potência da embarcação, que é realizado mediante o método do navio esbelto através do software Maxsurf Resistance.

Figura 11
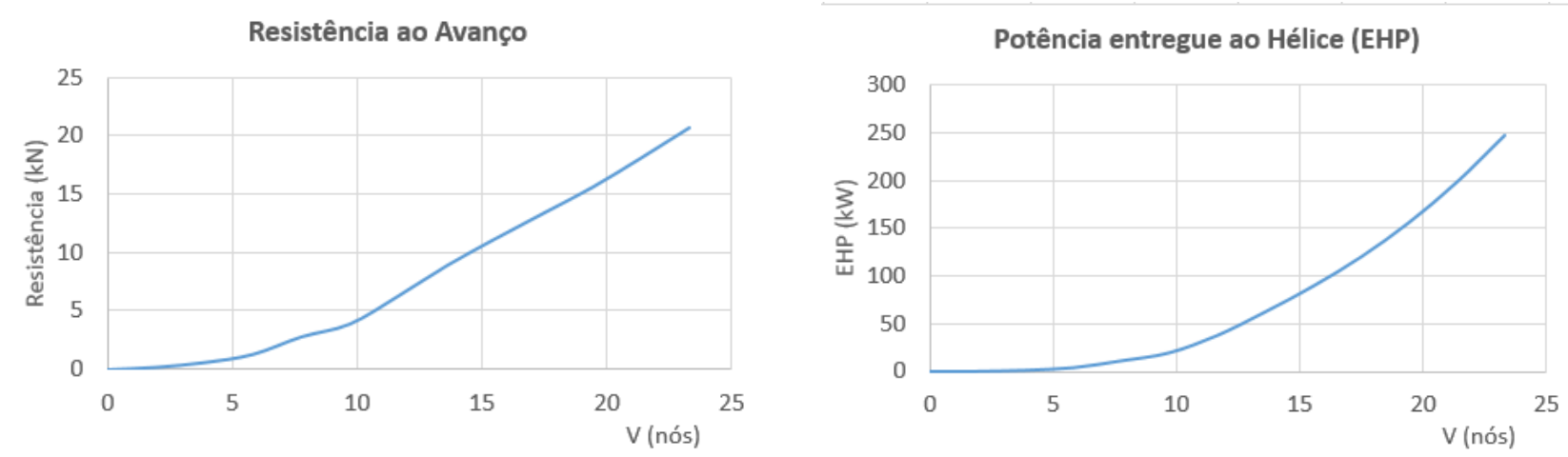

Curvas de Resistência ao Avanço e Potência entregue ao Hélice do Catamarã

Fonte: Autor

Posteriormente é possível definir a potência do motor, no caso deste trabalho é determinado dois motores Volvo Penta D6-400/DP, onde cada motor, fornece uma potência no eixo de $281 \mathrm{~kW}$. A seguir, determina-se o propulsor a ser utilizado, neste caso é definido um propulsor contra-rotativo com diâmetro de 37 centímetros.

Figura 12

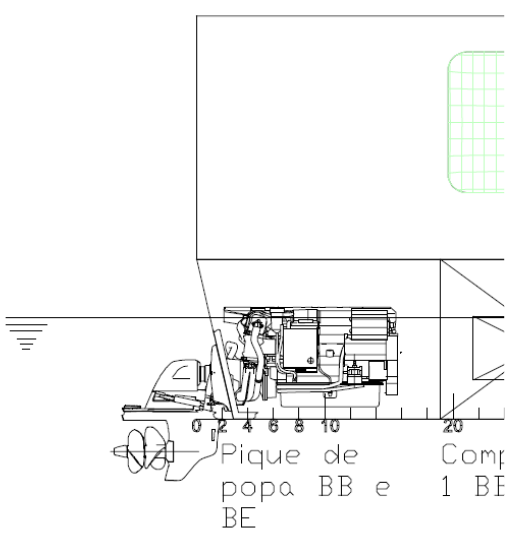

Motor e hélice instalados na popa de um dos cascos do catamarã Fonte: Autor 


\subsection{Viabilidade econômica}

A análise de viabilidade econômica consiste na obtenção de um valor de passagem para os usuários dentro do praticado em serviços de transporte fluvial, e que consiga cobrir todos os custos de construção e operação do catamarã. Estes custos são divididos em três partes: o custo de construção (ligado ao financiamento e construção da embarcação), o custo operacional (relacionado a tripulação, manutenção e reparo) e o custo de viagem (relacionado ao custo com combustível, custos portuários e outros).

O financiamento da embarcação é feito através do Sistema de Amortização Constante (SAC), onde a parcela é a amortização somada aos juros. O valor a ser financiado é $90 \%$ da embarcação, em um prazo de 10 anos. O tempo de vida útil da embarcação é de 25 anos. Com essas diretrizes, primeiro é necessário definir o valor da embarcação, inicialmente definido através de embarcações semelhantes e verificando posteriormente no projeto conceitual desenvolvido por RORIZ (2018), sendo este valor de $\mathrm{R} \$ 2.900 .000,00$. Com todos os custos e receitas definidos, foi elaborada uma planilha contendo o fluxo de caixa dentro do tempo de vida útil da embarcação, Figura 14.

Figura 14

\begin{tabular}{|c|c|c|c|c|c|c|c|c|c|}
\hline ANO & $\begin{array}{c}\text { Capital Próprio } \\
\text { (R\$) }\end{array}$ & $\begin{array}{c}\text { Saldo Devedor } \\
\text { [Rः] }\end{array}$ & $\begin{array}{c}\text { Amortização } \\
\text { (R\$] }\end{array}$ & Juros (R\$) & $\begin{array}{l}\text { Prestação } \\
\text { (R\$) }\end{array}$ & $\begin{array}{c}\text { Prestação } \\
\text { TRCorreção[R\$] }\end{array}$ & $\begin{array}{c}\text { Custo Anual } \\
\text { [R\$] }\end{array}$ & $\begin{array}{c}\text { Custo Presente } \\
\text { [R\$] }\end{array}$ & Receita (R\$) \\
\hline 0 & $286.615,18$ & $2.579 .536,62$ & & & & & $286.615,18$ & $286.615,18$ & 0,00 \\
\hline 1 & & & $257.953,66$ & $154.772,20$ & $412.725,86$ & $441.616,67$ & $2.179 .362,50$ & $1.981 .238,64$ & $2.431 .804,02$ \\
\hline 2 & & & $257.953,66$ & $139.294,98$ & $397.248,64$ & $425.056,04$ & $2.162 .801,88$ & $1.787 .439,57$ & \begin{tabular}{|l|}
$2.431 .804,02$ \\
\end{tabular} \\
\hline 3 & & & $257.953,66$ & $123.817,76$ & $381.771,42$ & $408.495,42$ & $2.146 .241,25$ & $1.612 .502,82$ & $2.431 .804,02$ \\
\hline 4 & & & $257.953,66$ & $108.340,54$ & $366.294,20$ & $391.934,79$ & $2.129 .680,63$ & $1.454 .600,53$ & $2.431 .804,02$ \\
\hline 5 & & & $257.953,66$ & $92.863,32$ & $350.816,98$ & $375.374,17$ & $2.113 .120,00$ & $1.312 .081,27$ & $2.431 .804,02$ \\
\hline 6 & & & $257.953,66$ & $77.386,10$ & $335.339,76$ & $358.813,54$ & \begin{tabular}{|l|}
$2.096 .559,38$ \\
\end{tabular} & $1.183 .453,11$ & $2.431 .804,02$ \\
\hline 7 & & & $257.953,66$ & $61.908,88$ & $319.862,54$ & $342.252,92$ & \begin{tabular}{|l|}
$2.079 .998,75$ \\
\end{tabular} & $1.067 .368,25$ & $2.431 .804,02$ \\
\hline 8 & & & $257.953,66$ & $46.431,66$ & $304.385,32$ & $325.692,29$ & $2.063 .438,13$ & $962.609,12$ & $2.431 .804,02$ \\
\hline 9 & & & $257.953,66$ & $30.954,44$ & $288.908,10$ & $309.131,67$ & \begin{tabular}{|c|}
$2.046 .877,50$ \\
\end{tabular} & 868.075 .87 & $2.431 .804,02$ \\
\hline 10 & & & $257.953,66$ & $15.477,22$ & $273.430,88$ & $292.571,04$ & \begin{tabular}{|l|}
$2.030 .316,88$ \\
\end{tabular} & $782.775,05$ & $2.431 .804,02$ \\
\hline 11 & & & & & & & $1.737 .745,83$ & $609.069,31$ & $2.431 .804,02$ \\
\hline 12 & & & & & & & $1.737 .745,83$ & $553.699,38$ & $2.431 .804,02$ \\
\hline 13 & & & & & & & $1.737 .745,83$ & $503.363,07$ & $2.431 .804,02$ \\
\hline 14 & & & & & & & $1.737 .745,83$ & $457.602,79$ & $2.431 .804,02$ \\
\hline 15 & & & & & & & $1.737 .745,83$ & $416.002,54$ & $2.431 .804,02$ \\
\hline 16 & & & & & & & $1.737 .745,83$ & $378.184,12$ & $2.431 .804,02$ \\
\hline 17 & & & & & & & $1.737 .745,83$ & $343.803,75$ & $2.431 .804,02$ \\
\hline 18 & & & & & & & $1.737 .745,83$ & $312.548,86$ & $2.431 .804,02$ \\
\hline 19 & & & & & & & $1.737 .745,83$ & $284.135,33$ & $2.431 .804,02$ \\
\hline 20 & & & & & & & $1.737 .745,83$ & $258.304,85$ & $2.431 .804,02$ \\
\hline 21 & & & & & & & $1.737 .745,83$ & $234.822,59$ & $2.431 .804,02$ \\
\hline 22 & & & & & & & $1.737 .745,83$ & $213.475,08$ & $2.431 .804,02$ \\
\hline 23 & & & & & & & $1.737 .745,83$ & 194.068 .25 & $2.431 .804,02$ \\
\hline 24 & & & & & & & $1.737 .745,83$ & 176.425 .69 & $2.431 .804,02$ \\
\hline 25 & & & & & & & $1.737 .745,83$ & $160.386,99$ & $2.431 .804,02$ \\
\hline & & & & & & & & $18.394 .651,99$ & 60.795 .100 .44 \\
\hline
\end{tabular}

Custos para o financiamento da embarcação.

Fonte: Autor

A viabilidade econômica do projeto é analisada mediante o Valor Presente Líquido (VPL), considerando duas situações, a primeira considerando que ao final da vida útil o VPL é igual a zero, ou seja, o armador não vai obter lucro e também não terá prejuízo, então esse é o valor mínimo da passagem. A segunda situação é quando adiciona-se um fator de lucro ao cálculo de VPL e neste caso determina-se o valor da passagem e o seu lucro ao final da vida útil, sendo necessário ao final fazer uma pesquisa de mercado para verificar se este valor é aplicável. Na primeira situação encontrou-se que o valor da passagem para zerar o VPL seria de $R \$ 7,55$, logo foi adicionado um fator de lucro de $20 \%$, onde o valor da passagem passou para $\mathrm{R} \$ 9,06$, obtendo um VPL ao final da vida útil da embarcação de $R \$ 3.678 .930,40$.

Com o valor da passagem definido em $\mathrm{R} \$ 9,06$, foi feita uma pesquisa de mercado, infelizmente no Brasil não existe em operação um serviço urbano de transporte fluvial semelhante para realizar uma comparação direta do preço da passagem. Por esse motivo, o valor da passagem obtido foi dividido pela distância do percurso, desta forma o valor da passagem deste projeto ficou 
dentro do praticado em outras regiões com serviço de transporte por embarcação, como mostrado na Tabela 5.

Tabela 3

\begin{tabular}{|l|l|l|l|}
\hline Rota & Distância (km) & Valor (R\$) & R\$/km \\
\hline Salvador - Itaparica & 13,6 & 6,70 & 0,493 \\
\hline Santos - Guarujá & 0,45 & 2,10 & 4,667 \\
\hline Joinville - Vila da Glória & 1,2 & 1,90 & 1,583 \\
\hline Santos - Vicente de Carvalho & 2 & 1,50 & 0,75 \\
\hline Cananéia - Ariri & 37,6 & 7,70 & 0,205 \\
\hline Petrolina - Juazeiro & 0,7 & 1,75 & 2,5 \\
\hline Porto Alegre - Guaíba & 13,9 & 10,70 & 0,77 \\
\hline Recife - Rio Capibaribe & 11 & 9,06 & 0,82 \\
\hline & Valor das passagens em outras regiões. & \\
\hline & \multicolumn{2}{|c}{ Fonte: Autor } & \\
\hline
\end{tabular}

\section{Conclusão}

Atingiu-se o objetivo principal de desenvolver o projeto conceitual de uma embarcação para o transporte de passageiros pelo Rio Capibaribe que atende os requerimentos do Projeto Navega Recife no corredor oeste e assim oferecer à população um transporte alternativo, de custo competitivo e de alta agilidade com relação ao tempo de deslocamento. Este trabalho serve para demonstrar a importância da navegação fluvial principalmente em um país como o Brasil, que possui um vasto número de rios que percorrem vários estados.

Ao longo do presente trabalho foram descritas as principais características para o desenvolvimento do projeto de uma embarcação construída em fibra de vidro, onde o ponto de partida do projeto foi definir as dimensões principais através de embarcações semelhantes iniciando apenas com o número de passageiros. Com as dimensões principais pré-determinadas foram feitas análises para definir as linhas de forma de um casco eficiente e que estivesse dentro dos parâmetros pré-determinados. Com o casco definido foi feita a análise de viabilidade econômica, que definiu o financiamento e o valor da passagem para obter lucro. Em seguida foi feito o dimensionamento estrutural, análise de estabilidade intacta, dimensionamento do propulsor e por fim o arranjo geral. No final deste dimensionamento, parâmetros anteriormente adotados através de embarcações semelhantes foram revisados devido à natureza iterativa do projeto.

A implementação do Projeto Navega Recife com o catamarã projeto no presente trabalho, produziria uma melhoria substancial no transporte urbano de Recife e exploraria o potencial econômico do Rio Capibaribe e principalmente seria uma oportunidade para revitalizar-lo.

\section{Referências}

ABREU, D. Investimentos federais em hidrovias e ferrovias caem mais de $\mathbf{7 0 \%}$ nos últimos seis anos. Disponível em: <https://goo.gl/yLhX7T>. Acesso em: 7 nov. 2017.

ALMEIDA, C. E \& BRIGHETTI, G. Navegação Interior e Portos Marítimos. Notas de Aula PHD 523. São

AMERICAN BUREAU OF SHIPPING. HIGH-SPEED CRAFT. 2017.

ANGÉlICA, M. A Ponte no Papel: Atravessando a História de Recife nos Mapas dos Séculos XVII e XVIII. 2011

ASSOCIAÇÃO BRASILEIRA DE NORMAS TÉCNICAS. NBR 5413 lluminância de interiores. 
CAMARA, C. M. et al. Navegação Fluvial em Áreas Urbanas. 2014

CAMARA, E. Rios do Recife - Entenda a Veneza Brasileira. Disponível em: <http://visitarecife.com.br/rios-do-recife/>. Acesso em: 23 out. 2018.

CAVALCANTI, M. Governo abre nova licitação do projeto de navegabilidade do Capibaribe. Disponível em: <https://goo.gl/xxEdw8>. Acesso em: 7 nov. 2017.

COSTA, Luiz Sergio Silveira. As Hidrovias Interiores no Brasil. 2o edição, Editora Femar, 2001.

COSTA, Luiz Sergio Silveira. As Hidrovias Interiores no Brasil. 2o edição (2001) Editora Femar.

DE ARAUJO, B. et al. Impactos Sócio- Espaciais do Transporte de Passageiros no Projeto de Navegabilidade do rio Capibaribe: Estação Dois Irmãos (BR-101, SHOPPING NORTE). Revista Movimentos Sociais e Dinâmicas Espaciais, Recife, 1 fev. 2015.

GOVERNO DO ESTADO DE PERNAMBUCO. Projeto Rios da Gente. (Secretaria das Cidades), Recife: 2016.

HOLANDA, M. O. A Legislação Ambiental e a Conservação da Bacia Hidrográfica do Rio Capibaribe: os Paradigmas Socioambientais do Baixo Curso. 2012. Dissertação (Mestrado Profissional) - Faculdade de Ciências da Administração de Pernambuco, Universidade de Pernambuco, Recife, 2012.

KWAKERNAAK, L. et al. Contra-rotating propellers. 2012

LEWIS, E. Principles of Naval Architecture. Jersey: The Society of Naval Architects and Marine Engineers, 1988.

MINISTÉRIO DOS TRANSPORTES, P. E A. C. Transporte 2016. BRASÍLIA: 2008.

NASCIMENTO , N. Sem controle, poluição do Rio Capibaribe ameaça espécies. LeiaJá, Recife, p. 1-2, 16 mar. 2017. Disponível em: https://m.leiaja.com/noticias/2017/03/16/semcontrole-poluicao-do-rio-capibaribe-ameaca-especies/. Acesso em: 22 jul. 2019.

NASSEH, J. Manual de Construção de Barcos. $4^{\text {a }}$ ed. Rio de Janeiro: 2011.

NOTES, M. What is gross tonnage, net tonnage, light ship or light weight, dead weight tonnage? Disponível em: <http://marinenotes.blogspot.com/2012/07/what-is-gross-tonnage-nettonnage-light.html>. Acesso em: 6 jun. 2018.

POMPERMAYER, F.; NETO, C.; PAULA, J. Hidrovias no Brasil: Perspectiva Histórica, Custos e Institucionalidade. 2014

ROCHA, E. G.; SOUZA, C. A.; DALFIOR, V. A. O. Estudo de Viabilidade Econômica Financeira. 2016.

RORIZ, E. L. Projeto Conceitual de uma Embarcação de Passageiros para Navegação no Rio Capibaribe. 2018. Trabalho de Conclusão de Curso (Dissertação) - Curso de Engenharia Naval, Universidade Federal de Pernambuco -UFPE, Recife, 2018.

SANTANA, W. A.; TACHIBANA, T.-I. Caracterização dos elementos de um projeto hidroviário, vantagens, aspecots e impactos ambientais para a proposição de metodologias técnico-ambientais para o desenvolvimento do transporte comercial de cargas nas hidrovias brasileiras. Engevista, v. 6, n. 3, p. 75-85, 2004.

SANTOS, B.; FERRINHO, P.; ROMÃO, M. Malha Hidroviária: um Modo de Transporte ainda Pouco Explorado. 2011

São Paulo, SP: EPUSP, 2001.b. 71 p. FIALHO, G. O. M. Navegação no Brasil.

SOARES, R. Recife, a capital com o trânsito mais lento do País de novo. Disponível em: <https://goo.gl/XqRQ4d>. Acesso em: 23 out. 2018.

SOPRANIS, R. V. Catamarán para transporte de pasaje en aguas abrigadas. [s.I.] Escuela Técnica Superior de Ingenieros Navales, 2010. 